\title{
Drilling Load Model of an Inchworm Boring Robot for Lunar Subsurface Exploration
}

\author{
Weiwei Zhang, Shengyuan Jiang, Dewei Tang, Huazhi Chen, and Jieneng Liang \\ State Key Laboratory of Robotics and System, Harbin Institute of Technology, Harbin 150001, China \\ Correspondence should be addressed to Shengyuan Jiang; jiangshy@hit.edu.cn
}

Received 13 January 2017; Revised 24 April 2017; Accepted 9 May 2017; Published 1 June 2017

Academic Editor: Paul Williams

Copyright (c) 2017 Weiwei Zhang et al. This is an open access article distributed under the Creative Commons Attribution License, which permits unrestricted use, distribution, and reproduction in any medium, provided the original work is properly cited.

\begin{abstract}
In the past decade, the wireline robot has received increasing attention due to the advantages of light weight, low cost, and flexibility compared to the traditional drilling instruments in space missions. For the lunar subsurface in situ exploration mission, we proposed a type of wireline robot named IBR (Inchworm Boring Robot) drawing inspiration from the inchworm. Two auger tools are utilized to remove chips for IBR, which directly interacted with the lunar regolith in the drilling process. Therefore, for obtaining the tools drilling characteristics, the chips removal principle of IBR is analyzed and its drilling load model is further established based on the soil mechanical theory in this paper. And then the proposed theoretical drilling load model is experimentally validated. In addition, according to the theoretical drilling load model, this paper discusses the effect of the drilling parameters on the tools drilling moments and power consumption. These results imply a possible energy-efficient control strategy for IBR.
\end{abstract}

\section{Introduction}

Scientific targets such as the physical and mechanical properties and heat flux of regolith are critical evidences for human studying the planetary origin and evolution [1]. Drilling is an effective method and is widely utilized in the planetary subsurface exploration missions $[2,3]$. Though these missions are capable of sampling the regolith or rack by using of the drill with its inbuilt coring tube, these drills are generally designed less than two meters because of the constraints of power, payload, and volume. For obtaining more valuable and reliable scientific data, the depth of implementing investigation should be more than three meters which is beyond the significant thermal cycles [4]. If long drills such as MARTE [5] and SPECES [6] which coupled with multiple drill sections are utilized to achieve greater depth, they will unavoidably increase the mass and complexity of the system.

To sidestep the drawbacks of traditional drill, a type of wireline robot has been proposed for deep subsurface exploration. The wireline robot has the capability of accessing the target position in the planet and implementing scientific investigation by internal instruments. Compared with the traditional drill, the wireline robot does not have rigid connection to the surface but has a tether which provides the wireline robot with power and data communication [7]. According to the boring method of penetrating or excavating, the wireline robot can be classified as two types of penetrator and excavating robot. Serval penetrators such as MUPUS [8] (Rosetta mission), Insight [9] (InSight mission), and KRET [10] (future lunar robotic mission) were proposed, and they can penetrate into the planetary subsurface by using of the impact driven by penetrator's internal hammer mechanism. Besides that, a bioinspired penetrator based on the working mechanism of wood wasp ovipositors was proposed for avoiding the needed external force in the space missions [11]. Although these penetrators have advantages of light weight and small dimensions, it is difficult for them to penetrate hard regolith or rocks and thus they are just suitable for subsurface exploration of the shallow depth in relatively loose regolith. Drawing inspiration from nature, several bioinspired excavating robots including IDDS [12], Auto-Gopher [13], and Earthworm-type robot [14] were proposed. The excavating robot can break and remove the regolith for making space and advancement, and it is generally equipped with anchor mechanism used to supply the enough down force when applied on the borehole wall. Although the excavating robot potentially has stronger drilling ability than the traditional drill and the penetrator, it also has the disadvantages in 


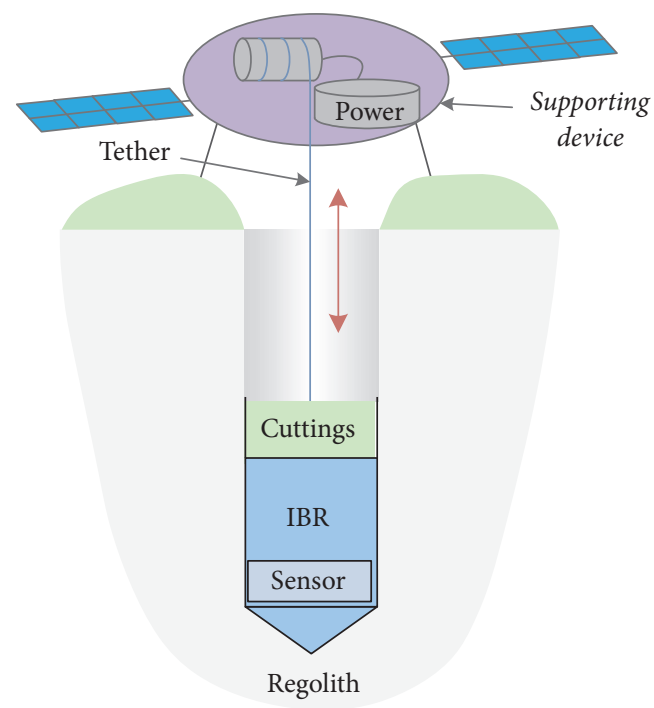

FiguRE 1: Subsurface exploration system.

complex operation and structure especially for a robotic mission.

Therefore, an Inchworm Boring Robot was proposed for China's lunar robotic subsurface exploration mission [15]. The IBR has two critical tools of drill bit used for cutting the regolith or rocks and the auger was used to remove the chips. In the case of energy limit, it is necessary to reasonably select operating parameters to reduce working resistance and energy consumption of IBR. Therefore, it is of great significance to study the interaction between tools and lunar regolith for tools design and motion control strategy. The interaction between drill bit and lunar soil or rock had already been analyzed [16, 17], so that this paper mainly focuses on the establishment of auger drilling load model based on the soil mechanics theory. According to the drilling load model, this paper takes the drilling moment and power consumption as the evaluation index and studies the drilling parameters matching which lays the foundation for the motion control strategy of IBR.

The remainder of the paper is organized as follows. The IBR and its working principle are introduced in Section 2. In Section 3, chips removal in the excavating mode and discharging mode are analyzed. Section 4 gives the establishment of the drilling load model of IBR. In Section 5, the drilling load model was experimentally validated and the effect of drilling parameters on the drilling load is analyzed for the future motion control strategy. Section 6 concludes this paper.

\section{Working Principle of IBR}

Subsurface exploration system shown in Figure 1 was proposed to implement scientific investigations of scientific targets such as the physical and mechanical properties and heat flux of lunar regolith. As depicted in Figure 1, the subsurface exploration system is mainly made up of IBR and supporting device. IBR automatically drills into planetary subsurface with the power supply of supporting device according to one tether. In the drilling process, the hard original regolith was broken into loose cuttings, and the cuttings were simultaneously conveyed to chamber at the end of IBR. Once the volume of cuttings accumulated in the chamber reaches the set value, IBR will return back to the surface and discharge the cuttings. In the investigating process, IBR can collect the scientific data by its inner sensors.

The IBR consists of three modules, excavating module, discharging module, and propulsion module, as shown in Figure 2(a). Excavating module was equipped with drill head and excavating auger: the drill head was used to break the original regolith or rocks into cuttings and the excavating auger was used to convey the cuttings to the storage room. The discharging module was just equipped with a discharging auger used to convey the cutting to the back of the IBR from storage room, while excavating module and discharging module can be fixed on the borehole wall by excavating anchor and discharging anchor, respectively. Propulsion module can provide linear motion for excavating module and discharging module.

One drilling process is composed of four steps as shown in Figure 2(b).

Step 1. Discharging anchor engages the borehole wall.

Step 2. Excavating module drills forward with rotating and penetrating motion. At the same time, the excavating auger rotates in the opposite direction.

Step 3. Excavating anchor engages the borehole and discharging anchor disengages the borehole wall.

Step 4. Discharging module drills forward with rotating and penetrating motion.

Repeat the steps; IBR realizes the function of continued drilling into the regolith. In Steps 2 and 4, the IBR is mainly focused on excavating forward and discharging the cuttings. And thus the two steps can be defined as excavating mode and discharging mode for IBR.

\section{Chips Removal of IBR}

According to the components of IBR, two augers, EA (excavating auger) and DA (discharging auger), were used to remove the cuttings produced by the breaking of regolith or rocks by the $\mathrm{DH}$ (drill head). The structure parameters of the EA and DA are shown in Figure 3.

According to the working principle of IBR, two working modes of excavating mode and discharging mode can be defined in the whole drilling process as shown in Figure 4. In order to analyze the principle of chip removal for the two working modes, the following three assumptions need to be made:

(i) The flow channels (auger groove) of EA and DA are fully filled with the cuttings in the whole drilling process. 


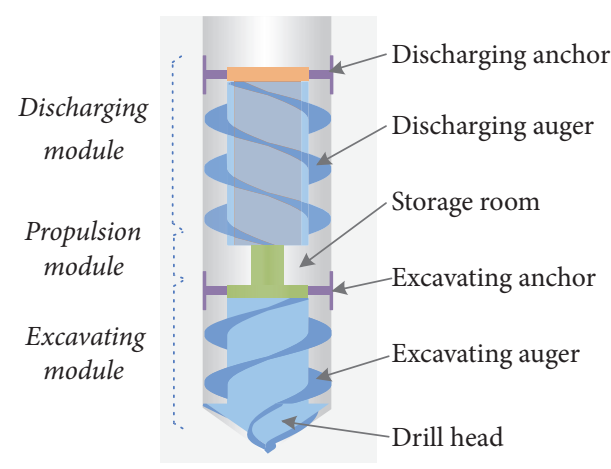

(a) Components

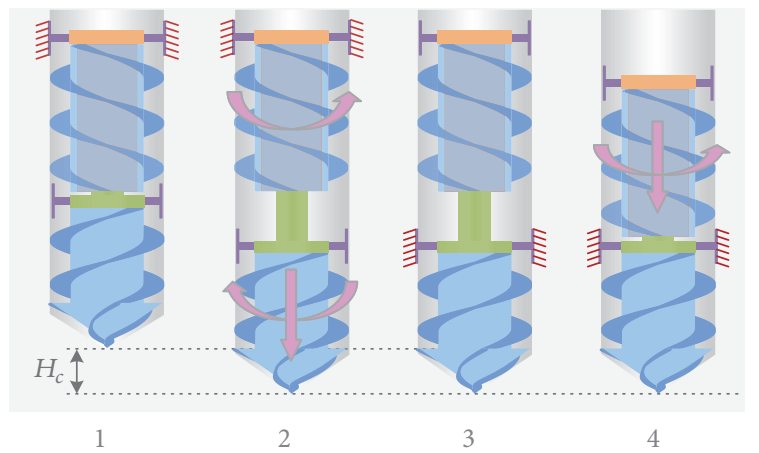

(b) Drilling process

FIGURE 2: Components and drilling process of IBR.

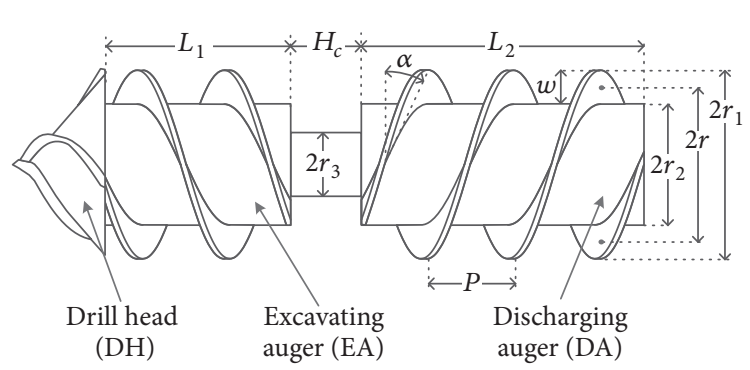

FIGURE 3: Structure parameters of EA and DA $\left(r_{1}, r_{2}\right.$, and $r$ are the inner radius, outer radius, and middle radius of the screw flight, resp. $\alpha$ is the screw angle. $N$ is the number of the screw flights. $L_{1}$ and $L_{2}$ are the lengths of EA and DA, resp. $r_{3}$ is the inner radius of the storage room; $H_{c}$ is the maximal height of the storage room. $P$ is the screw pitch. $w$ is the width of the screw flight).

(ii) The regolith is relatively compact compared with the cuttings; its bulk density is $\rho_{1}$. The compression among the cuttings on the screw flight is not taken into account, so that the cuttings have a constant bulk density $\rho_{2}$ in the analysis.

(iii) The cuttings in the storage room are probably compressed when the cuttings are not timely removed by DA, so that the bulk density of the compact cuttings increases and it is noted as $\rho_{3}$.

3.1. Discharging Mode. In the discharging mode, EA stops working and the DA conveys the compact cuttings to the end of IBR from the storage room. DA rotates and penetrates relative to the borehole; the rotary speed and penetrating velocity are $\omega_{2}$ and $v_{2}$, respectively. For one certain instant, the motion of cuttings on the screw flight is equivalent to a planer motion and the instantaneous velocities are given in Figure 5.

In Figure 5, $v_{n}$ represents the peripheral velocity of the auger, and $v_{n}=\omega_{2} r . v_{r}$ is the sliding velocity of the cuttings relative to the auger. $v_{a}$ is resultant velocity of cuttings relative to the borehole, which has an incline angle $\beta_{2}$ and is composed of the velocities $v_{n}, v_{2}$, and $v_{r}$. Therefore, from the whole process of conveying, the cuttings are lifted and do upward spiral motion with an opposite direction to the screw flight. As shown in Figure 5, $v_{a}$ can be resolved into the useful lifting velocity $v_{f 2}$ and the peripheral velocity $v_{h 2}$ of the cuttings. Hence, the velocity relations of cuttings on the screw flight can be illustrated as follows:

$$
\begin{aligned}
v_{n}-v_{r} \cos \alpha & =v_{h 2} \\
v_{r} \sin \alpha-v_{2} & =v_{f 2} \\
v_{f 2} & =v_{h 2} \tan \beta_{2} .
\end{aligned}
$$

Substituting $v_{n}=\omega_{2} r$ into (1) and eliminating the velocity $v_{r}$, the peripheral velocity $v_{h 2}$ and the lifting velocity $v_{f 2}$ of the cuttings can be solved:

$$
\begin{aligned}
& v_{h 2}=\frac{\omega_{2} r \tan \alpha-v_{2}}{\tan \alpha+\tan \beta_{2}} \\
& v_{f 2}=\frac{\left(\omega_{2} r \tan \alpha-v_{2}\right) \tan \beta_{2}}{\tan \alpha+\tan \beta_{2}} .
\end{aligned}
$$

In Figure 4(b), $\Phi_{2}$ is the cuttings mass flow rate from the storage room to the flow channel of DA. $\Phi_{2}$ can be given as the reduced cuttings mass flow rate $\rho_{3} A_{3} v_{2}$ in the storage room and the cuttings mass flow rate $\rho_{2} A_{2}\left(v_{f 2}+v_{2}\right)$ in the flow channel of DA. Therefore, the incline angle $\beta_{2}$ can be deduced based on the equation $\rho_{3} A_{3} v_{2}=\rho_{2} A_{2}\left(v_{f 2}+v_{2}\right)$.

$$
\beta_{2}=\arctan \frac{\left(\rho_{3} A_{3}-\rho_{2} A_{2}\right) v_{2}}{\rho_{2} A_{2} \omega_{2} r-\rho_{3} A_{3} v_{2} \cot \alpha},
$$

where $A_{2}$ represents the cross-sectional area of cuttings flow channel in DA or EA and $A_{2}=\pi\left(r_{1}{ }^{2}-r_{2}{ }^{2}\right) \cdot A_{3}$ represents the cross-sectional area of cuttings flow channel in the storage room and $A_{3}=\pi\left(r_{1}{ }^{2}-r_{3}{ }^{2}\right)$.

3.2. Excavating Mode. In the excavating mode, $\mathrm{DH}$ breaks the original regolith into cuttings and these cuttings are then conveyed to the storage room by EA with the rotary and penetrating motion. The produced cuttings are filled and compressed in the storage room, and some of them are removed with the rotary movement of DA. As shown in 


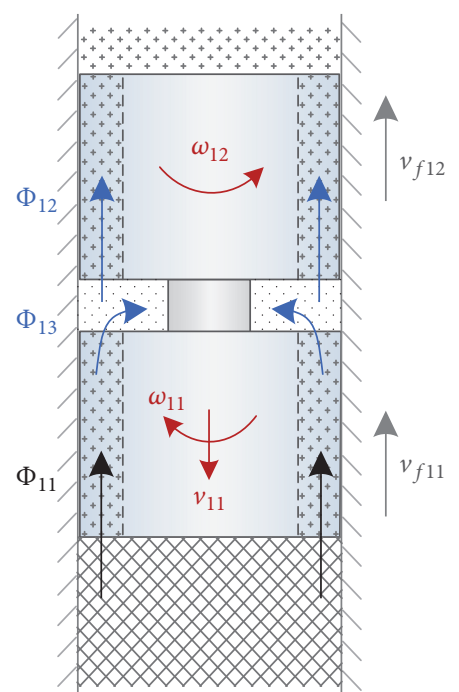

Regolith

Cuttings

Compact cuttings

(a) Excavating mode

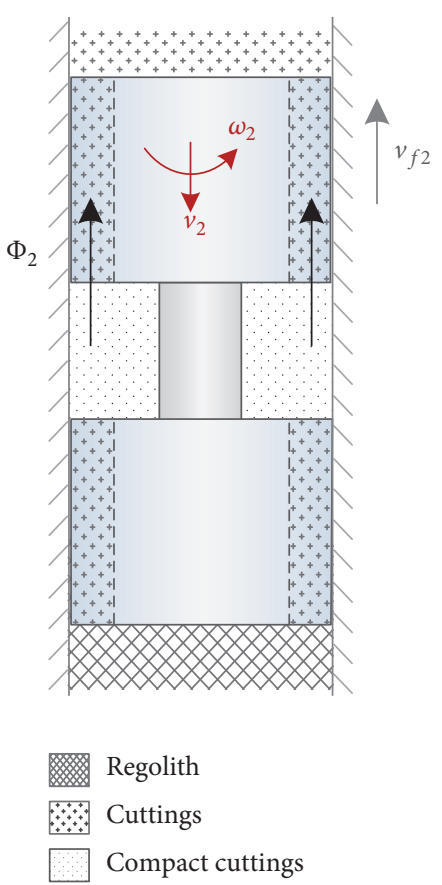

(b) Discharging mode

FIGURE 4: IBR working mode.

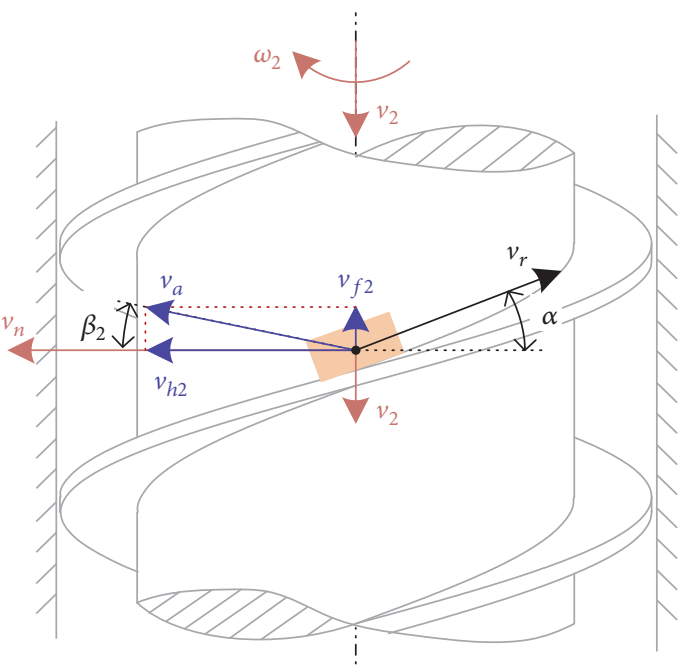

Figure 5: Velocities of cuttings on the screw flight.

Figure $4(\mathrm{a}), v_{f 11}$ and $v_{f 12}$ are the vertical upward velocities of cuttings in the EA and DA flow channel. Based on (3), the two velocities can be calculated as follows:

$$
\begin{aligned}
& v_{f 11}=\frac{\left(\omega_{11} r \tan \alpha-v_{11}\right) \tan \beta_{11}}{\tan \alpha+\tan \beta_{11}} \\
& v_{f 12}=\frac{\omega_{12} r \tan \alpha \tan \beta_{12}}{\tan \alpha+\tan \beta_{12}},
\end{aligned}
$$

where $\omega_{11}$ and $v_{11}$ represent the rotary speed and penetrating velocity of EA, respectively. $\omega_{12}$ represents the rotary speed of DA. $\beta_{11}$ and $\beta_{12}$ are, respectively, the incline angles of cuttings resultant velocities in the EA and DA. As can be seen in Figure 4(a), $\Phi_{11}$ is the mass flow rate of the chips from the original regolith to the flow channel in EA. $\Phi_{11}$ can be given as the produced cuttings mass flow rate $\rho_{1} A_{1} v_{11}$ from the original regolith and the cuttings mass flow rate $\rho_{2} A_{2}\left(v_{f 11}+v_{11}\right)$ in the flow channel in EA. In the excavating mode, the mass flow rate $\Phi_{11}$ was divided into two parts: the mass flow rate $\Phi_{12}$ of the flow channel in the DA and the mass flow rate $\Phi_{13}$ in the storage room. $\Phi_{12}$ and $\Phi_{13}$ can be expressed as $\rho_{2} A_{2} v_{f 12}$ and $\rho_{3} A_{3} v_{11}$, respectively. Therefore, two equations can be obtained as $\rho_{1} A_{1} v_{11}=\rho_{2} A_{2}\left(v_{f 11}+v_{11}\right)$ and $\Phi_{11}=\Phi_{12}+\Phi_{13}$, and the incline angles $\beta_{11}$ and $\beta_{12}$ are deduced as shown in the following equation:

$$
\begin{aligned}
& \beta_{11}=\arctan \frac{\left(\rho_{1} A_{1}-\rho_{2} A_{2}\right) v_{11}}{\rho_{2} A_{2} \omega_{11} r-\rho_{1} A_{1} v_{11} \cot \alpha} \\
& \beta_{12}=\arctan \frac{\left(\rho_{1} A_{1}-\rho_{3} A_{3}\right) v_{11}}{\rho_{2} A_{2} \omega_{12} r-\left(\rho_{1} A_{1}-\rho_{3} A_{3}\right) v_{11} \cot \alpha},
\end{aligned}
$$

where $A_{1}$ represents the cross-sectional area of the borehole and $A_{1}=\pi r_{1}^{2}$.

\section{Drilling Load Model of IBR}

4.1. Soil-Auger Interaction. For obtaining the soil-auger interaction model, a soil element with a small angle $d \theta$ was taken as the analyzed object on the screw flight as shown in Figure 6(a). In Figure 6(b), the distance from the center of soil element to the central axis of the auger is $r . w$ and $H$ are the height and width of the soil element, respectively. The left 


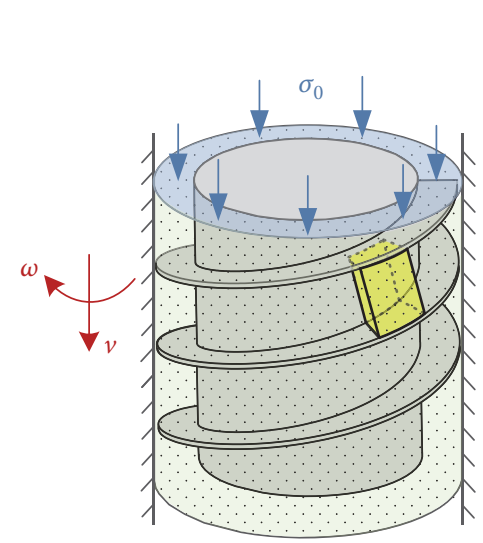

(a) Soil element

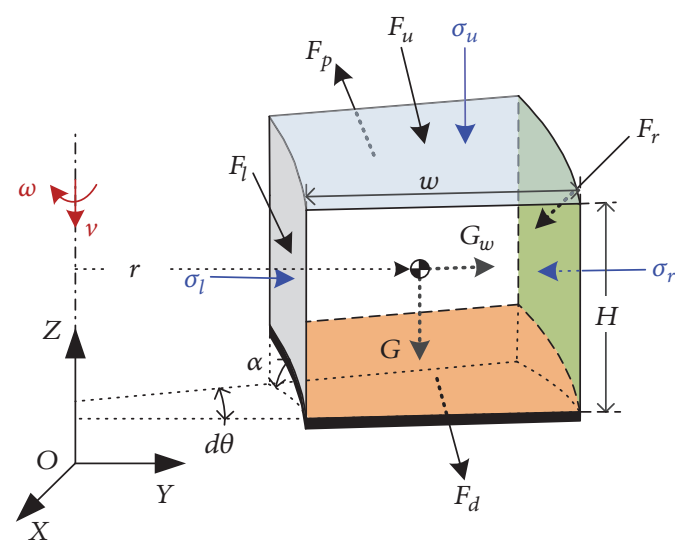

(b) Forces in space

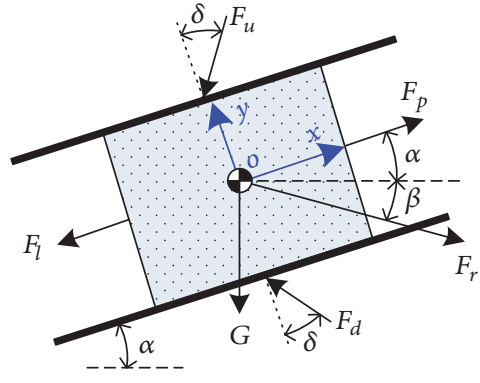

(c) Forces on plane

FIgURE 6: Forces analysis of chips element.

lateral surface of the soil element represents the auger stem surface, its area was noted by $A_{L}$, and $A_{L}=H r_{2} \sec \alpha d \theta$. The right lateral surface of the soil element represents the borehole wall surface, its area was noted by $A_{R}$, and $A_{R}=$ $H r_{1} \sec \alpha d \theta$. The top and bottom surfaces of the soil element represent the lower and upper surfaces of the screw flight, and the area can be defined as $A_{F}: A_{F}=w r \sec \alpha d \theta$. The front and back surfaces representing the contact surface between the soil element and neighboring soil on the screw flight were noted by $A_{C}$, and $A_{C}=H w$. For the soil element, the pressure on the left, top, and right surfaces is, respectively, defined as $\sigma_{l}, \sigma_{u}$, and $\sigma_{r}$; the difference pressure acting on the front and back surfaces is $d \sigma$.

These forces shown in Figure 6(b) applied on the soil element can be expressed on the plane as shown in Figure 6(c), and then the static equilibrium equation (7) can be carried out in the $x$ direction (the tangential direction of the screw flight) and the $y$ axial direction (the normal direction of the screw flight).

$$
\begin{aligned}
& F_{r} \cos (\alpha+\beta)+F_{p}-F_{l}-\left(F_{d}+F_{u}\right) \sin \delta-G \sin \alpha \\
& \quad=0 \\
& \left(F_{d}-F_{u}\right) \cos \delta-F_{r} \sin (\alpha+\beta)-G \cos \alpha=0
\end{aligned}
$$

where $F_{d}$ is the force of the soil element against the upper surface of the screw flight. $F_{l}$ is the frictional force of the soil element against the lateral surfaces of auger stem, and $F_{l}=\sigma_{l} A_{F} \tan \delta . F_{u}$ is the force of the soil element against the lower surface of the screw flight, and $F_{u}=\sigma_{u} A_{F} \sec \delta . F_{r}$ is the frictional force of the soil element against the hole wall, and $F_{r}=\sigma_{r} A_{R} \tan \varphi . F_{p}$ is the resultant force of neighboring soil applied on the soil element, and $F_{p}=d \sigma A_{C}$. $G$ is the element gravity, and $G=\rho_{2} H A_{F} g . G_{w}$ is the centrifugal force of the element, and $G_{w}=\rho_{2} H A_{F} v_{h}^{2} / r$. By substituting above forces into (7) and simplifying the equation, (8) can be obtained:

$$
\begin{aligned}
\frac{d \sigma}{d \theta} & =K_{l} \sigma_{l}+K_{u} \sigma_{u}+K_{r} \sigma_{r}+K_{c} \\
K_{l} & =\frac{r_{2} \tan \delta}{w \cos \alpha} \\
K_{u} & =\frac{2 r \tan \delta}{H \cos \alpha} \\
K_{r} & =\frac{r_{1} \cos (\alpha+\beta+\delta) \tan \varphi}{-w \cos \delta \cos \alpha}, \\
K_{c} & =\rho_{2} g r(\tan \alpha+\tan \delta),
\end{aligned}
$$

where $\delta$ is the friction angle between soil and metal and $\varphi$ is the internal friction angle of the soil.

The average stress $\sigma_{p}$ caused by the soil gravity on the four lateral surfaces of the soil element can be calculated as $\sigma_{p}=$ $\rho_{2} g H K_{0} \cos \alpha / 2$ based on the soil mechanical theory, where $K_{0}$ is the stress coefficient and $K_{0}=1-\sin \varphi$ [18]. The stress $\sigma_{a}$ caused by the centrifugal force on the left and right lateral surfaces can be calculated as $\sigma_{a}=\rho_{2} v_{h}{ }^{2} w / r$. According to the compression properties of soil, the stress $\sigma$ will produce additional compressive stress on the surface of soil element. And the additional compressive stresses on the left, top, and right lateral surfaces are $K \sigma$, where $K$ is the stress transfer coefficient and $K=(1-\sin \varphi) /(1+\sin \varphi)$ [18]. Therefore, under the action of its own gravity, centrifugal force, and the additional stress, the stresses applied on the left, top, and right surfaces are deduced as follows:

$$
\begin{aligned}
& \sigma_{l}=\sigma_{p}-\sigma_{a}+K \sigma \\
& \sigma_{u}=K \sigma \\
& \sigma_{r}=\sigma_{p}+\sigma_{a}+K \sigma .
\end{aligned}
$$




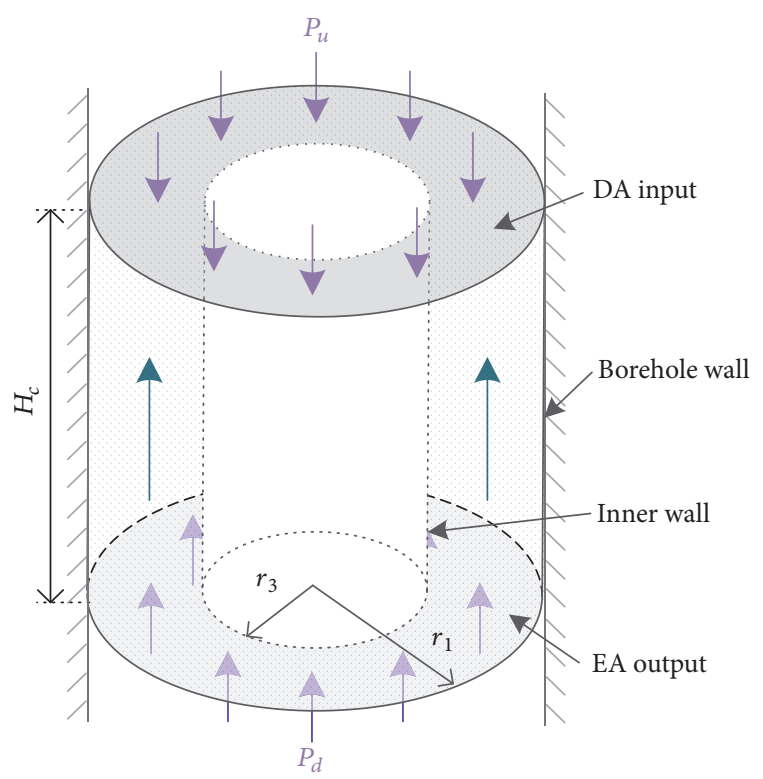

FIGURE 7: Stress of regolith in the storage room.

Substituting (9) into (8) and solving the differential equation, the explicit expression of the stress $\sigma$ can be obtained:

$$
\begin{aligned}
\sigma & =\left(\sigma_{0}+B_{s}\right) \exp \left(A_{s} \theta\right)-B_{s} \\
A_{s} & =K\left(K_{l}+K_{r}+K_{u}\right), \\
B_{s} & =\frac{K_{l}\left(\sigma_{P}-\sigma_{a}\right)+K_{r}\left(\sigma_{P}+\sigma_{a}\right)+K_{c}}{K\left(K_{l}+K_{r}+K_{u}\right)},
\end{aligned}
$$

where $\sigma_{0}$ represents the preload acting on top of the auger flow channel.

4.2. Drilling Moments of Tools. From (12), the stress state of the cuttings on the screw flight is affected by $\sigma_{0}$ which is the preload actnig on top of the auger flow channel. Therefore, it is necessary to analyze the stress of the regolith in the storage room and then give the obstructive stress acting on the top of EA flow channel. As shown in Figure 7, in the excavating mode, the cuttings discharged from EA were deposited in the storage and compressed, resulting in compressive stress $P_{u}$ inside the cuttings. At the same time, the cuttings in the storage room were pushed up by the newly generated cuttings discharged from EA. As a result of the preload $P_{u}$ and the fact that the frictions between the regolith and walls included borehole wall and the inner wall, the extrusion stress $P_{d}$ was generated on the bottom of the storage room.

Based on the hyperbolic relation of soil strain and stress assumed in the Duncan-Chang model [19] and the relation of soil strain and void ratio in the condition of confined consolidation test, an $e-p$ compression mode is established as shown in the following equation:

$$
e_{3}=e_{2}-\frac{\left(1+e_{2}\right) P_{u}}{A_{p}+B_{p} P_{u}},
$$

where $e_{2}$ and $e_{3}$ are the void ratios of the cuttings and the compressed cuttings in the storage room and $e_{2}=\rho_{s} / \rho_{2}-1$ and $e_{3}=\rho_{s} / \rho_{3}-1 . \rho_{s}$ is the granular density of regolith. $A_{p}$ and $B_{p}$ are the unknown coefficients that need to be determined by the confined compression test. By substituting $e_{2}$ and $e_{3}$ into (11), $P_{u}$ is calculated as follows:

$$
P_{u}=\frac{\left(\rho_{3}-\rho_{2}\right) A_{p}}{\rho_{3}-\left(\rho_{3}-\rho_{2}\right) B_{p}} .
$$

Based on Janssen's method [20] and considering the inner wall friction, the stress $P_{d}$ is calculated by the following equation:

$$
\begin{aligned}
P_{d} & =\frac{\rho_{3} g}{E}\left(\exp \left(H_{c} E\right)-1\right)+P_{u} \exp \left(H_{c} E\right) \\
E & =\frac{2 \pi K\left(r_{3} \tan \delta+r_{1} \tan \varphi\right)}{A_{3}} .
\end{aligned}
$$

In the conveying process of cuttings, the forces of $F_{l}, F_{u}$, and $F_{d}$ acting on auger will produce the resisting moments which can be, respectively, expressed as $F_{l} r_{2} \cos \alpha, F_{u} r \sin (\delta-$ $\alpha$ ), and $F_{d} r \sin (\delta+\alpha)$. By integrating the sum of above three resisting moments in the longitudinal direction, the total resisting moment $M$ of auger can be deduced as follows:

$$
\begin{aligned}
M & =N \int_{0}^{\theta_{m}}\left(K_{m l} \sigma_{l}+K_{m u} \sigma_{u}+K_{m r} \sigma_{r}+K_{m c}\right) d \theta \\
K_{m l} & =H r_{2}{ }^{2} \tan \delta, \\
K_{m u} & =2 w r^{2} \tan \delta \\
K_{m r} & =H r_{1} r \sin (\alpha+\beta) \sin (\alpha+\delta) \tan \varphi \sec \alpha \sec \delta \\
K_{m c} & =\rho_{3} g w H r^{2} \sec \delta \sin (\alpha+\delta),
\end{aligned}
$$

where $\theta_{m}$ represents the angle of the screw flight: $\theta_{m}=$ $2 \pi L / P$. From the soil-auger interaction analysis, $M$ is the function of the parameters including $\sigma_{0}, \omega, v$, and $\beta$, which can be noted as $M\left(\sigma_{0}, \omega, v, \beta\right)$. In the excavating mode, the drilling moment $M_{1}$ of EA can be obtained by substituting the parameters $P_{d}, \omega_{11}, v_{11}$, and $\beta_{11}$ into the function of $M$. In the discharging mode, there is no preload acting on the cuttings output port of the DA, and the drilling moment $M_{2}$ of EA can also be obtained by substituting the parameters $\omega_{2}, v_{2}$, and $\beta_{2}$ into the function of $M$. Therefore, the drilling moments $M_{1}$ and $M_{2}$ can be calculated as follows:

$$
\begin{aligned}
& M_{1}=M\left(P_{d}, \omega_{11}, v_{11}, \beta_{11}\right) \\
& M_{2}=M\left(0, \omega_{2}, v_{2}, \beta_{2}\right) .
\end{aligned}
$$

\section{Experiments and Model Validation}

\subsection{Drilling Test Bed}

5.1.1. Mechanical System. For testing the drilling load of EA and DA, a drilling test bed shown in Figure 8 was developed. The drilling test bed is composed of the stander, two rotary 


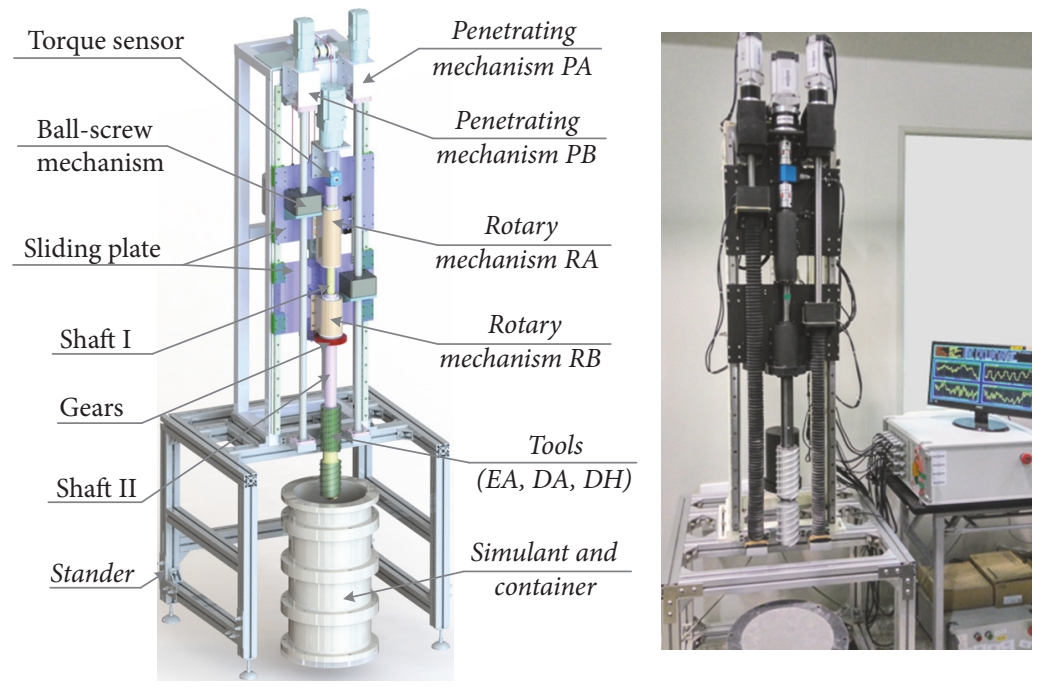

FIGURE 8: Drilling test bed.

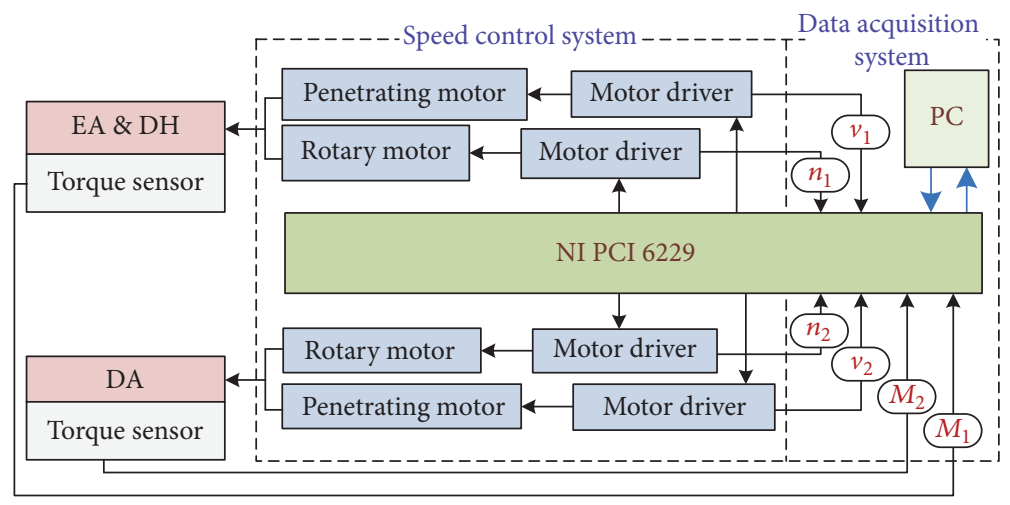

Figure 9: Speed control and data acquisition system.

mechanisms, RA and RB, and two penetrating mechanisms, $\mathrm{PA}$ and $\mathrm{PB}$.

The two rotary mechanisms RA and RB are, respectively, fixed on the two sliding plates. RA consists of rotary motor, torque sensor, and shaft I. Shaft I and the EA are directly driven by the rotary motor for the rotary motion with nominal rotary speed of $300 \mathrm{rpm}$ and nominal moment of $23 \mathrm{Nm}$. The rotary motor coupled with a reducer with the ratio of $1: 5$ is AC servo motor (MHMJ082) with $750 \mathrm{~W}$ power. For moment measurement of shaft I and EA, a torque sensor (HLT-20) which has the range of $0 \sim 20 \mathrm{Nm}$ was installed between the rotary motor and shaft I. The rotary mechanism $\mathrm{RB}$ consists of rotary motor, torque sensor, gear transmission, and shaft II. Shaft II and the DA are driven by the paralleled rotary motor and a gear transmission mechanism for the rotary motion with nominal rotary speed of $200 \mathrm{rpm}$ and nominal moment of $12 \mathrm{Nm}$. The rotary motor coupled with a reducer with the ratio of $1: 10$ is AC servo motor (MHMJ042) with $400 \mathrm{~W}$ power. For moment measurement of shaft II and DA, a torque sensor (HLT-10) which has the range of $0 \sim 10 \mathrm{Nm}$ was installed between the rotary motor and shaft II.
Two penetrating mechanisms are arranged in parallel and they are used to provide penetrating motion for EA and $\mathrm{DA}$, respectively. The two penetrating mechanisms have the same features; they consist of penetrating motor, ball-screw mechanism, and sliding plate. The ball-screw mechanism is driven by the penetrating motor and thus the two sliding plates can move linearly on the guide way for penetrating motion with a nominal velocity of $300 \mathrm{~mm} / \mathrm{min}$ and a nominal force of $500 \mathrm{~N}$. The penetrating motor coupled with a reducer with the ratio of $1: 5$ is also an AC servo motor (MHMJ042) with $100 \mathrm{~W}$ power.

5.1.2. Speed Control and Data Acquisition System. The test bed speed control and data acquisition system shown in Figure 9 has the function of motion control and signals and data acquisition. The two rotary motors and the two penetrating motors are, respectively, driven by the rotary drivers and penetrating drivers with the closed-loop speed control mode. In this control system, a data acquisition card (PCI 6229) produced by NI company was used to send control instructions to the motor drivers and also collect the signals of torque sensors $M_{1}$ and $M_{2}$, rotary speeds $n_{1}$ and $n_{2}$, and 


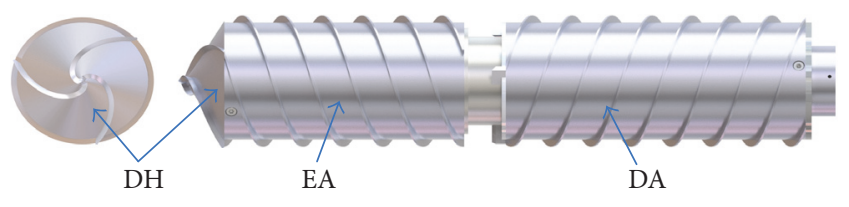

FIgure 10: Tools: DH, EA, and DA.

penetrating velocities $v_{1}$ and $v_{2}$, and then these signals can be sent to the PC.

5.1.3. Tools and Simulant. The tools including DH, EA, and DA are shown in Figure 10. In the auger EA and DA, the number of screw flights $N=3$; helix angel $\alpha=15.2^{\circ}$. The radii of the augers are $r_{1}=37 \mathrm{~mm}, r_{2}=33 \mathrm{~mm}$, and $r_{3}=25 \mathrm{~mm}$, and the lengths of EA and DA are $L_{1}=120 \mathrm{~mm}$ and $L_{2}=150 \mathrm{~mm}$.

The raw material of the simulant is the Cenozoic alkaline olivine basalt which is dehumidified and crushed into particles in size of $0.1 \sim 1 \mathrm{~mm}$. In the process of preparation, the raw material was steeply poured into the container and vibrated for the regolith simulant with consistent mechanical property along the height direction. The bulk densities of the regolith simulant and the cuttings are $2.18 \mathrm{~g} / \mathrm{cm}^{3}$ and $1.54 \mathrm{~g} / \mathrm{cm}^{3}$, respectively. The internal friction angle of simulant is $26^{\circ}$, the angle between simulant and tools is $17.6^{\circ}$, and the cohesion of the simulant is $0.05 \mathrm{kPa}$. The coefficients of $A_{p}$ and $B_{p}$ are, respectively, $2.2 \times 10^{5}$ and 5 determined by the confined compression test.

5.2. Experiments Results. In the drilling experiments, $H_{c}$ is set to $30 \mathrm{~mm}$, rotary speed $n_{11}$ is $60 \mathrm{rpm}$, and penetrating velocities $v_{11}$ and $v_{12}$ both are $30 \mathrm{~mm} / \mathrm{min}$. In order to investigate the effect of rotary speeds $n_{11}$ and $n_{12}$ on the drilling moments, $n_{11}$ was set to $20 \mathrm{rpm}, 40 \mathrm{rpm}$, and $60 \mathrm{rpm}$ and $n_{12}$ was set to $5 \mathrm{rpm}, 10 \mathrm{rpm}, 20 \mathrm{rpm}, 30 \mathrm{rpm}$, and $40 \mathrm{rpm}$ for drilling experiments and each drilling experiment will be repeated three times.

5.2.1. Drilling Experiments. In the drilling test, IBR takes $120 \mathrm{~s}$ for one drilling process; the excavating mode and the discharging mode both take $60 \mathrm{~s}$. As shown in Figure 11, DH is in contact with the simulant surface at $t=0 \mathrm{~s}$, EA is just fully penetrated into the simulant at $t=540 \mathrm{~s}$, and DA is just fully penetrated into the simulant at $t=1080 \mathrm{~s}$.

The drilling moments of the EA and DA are recorded by two torque sensors with $100 \mathrm{~Hz}$ sample rate. Figure 12 shows the drilling moments when $n_{11}=60 \mathrm{rpm}$ and $n_{12}=40 \mathrm{rpm}$, where the red curve represents the moment $M_{1 e}$ of EA in the excavating mode and the blue curve represents the moment $M_{2 e}$ of DA in the discharging mode.

From Figure 12, the whole drilling test can be divided into three stages: stages I, II, and III. In stage I, drill head breaks the simulant to cuttings; its drilling moment increases as the depth increases and reaches the maximum value $M_{11}$ at $t=60 \mathrm{~s}$. In stage II, drilling moment of the EA is slowly increasing, while the drilling moment of DA does not increase because it has not interacted with the simulant yet. In stage III, the EA has already drilled into the simulant; thus the storage room is unavoidably filled with cuttings, which will result in a sharp increase in drilling moment of EA. In whole stage III, the drilling moment of EA has reached the maximum value for four times $M_{12}, M_{13}, M_{14}$, and $M_{15}$, and this paper selects the maximum value of them as the contrast of theory results. At the same time, the drilling moment of DA is slowly increasing with the drilling depth gradually increasing and reaches the maximum $M_{21}$ at $t=1080 \mathrm{~s}$. According to the above analysis, the experimental drilling moment $M_{1}$ of EA and the experimental drilling moment $M_{2}$ of DA can be noted as follows:

$$
\begin{aligned}
& M_{1}=\max \left(M_{12}, M_{13}, M_{14}, M_{15}\right)-M_{11} \\
& M_{2}=M_{21} .
\end{aligned}
$$

5.2.2. Model Validation. Drilling moment $M_{1}$ of EA in excavating mode and the drilling moment $M_{2}$ of DA in discharging mode were calculated based on the drilling load model. Figure 13 gives the comparison between the theory curve and experimental results of the EA drilling moments. From Figure 13, the theoretical curve and the experimental results have the same tendency that the drilling moment of EA decreases with the increase of $n_{11}$ or $n_{12}$. There was good consistency between the theoretical model and experimental results with the RMS error of $0.148 \mathrm{Nm}, 0.141 \mathrm{Nm}$, and $0.121 \mathrm{Nm}$ when $n_{11}$ is $20 \mathrm{rpm}, 40 \mathrm{rpm}$, and $60 \mathrm{rpm}$, respectively. Figure 14 gives the comparison between the theory and experimental results of the DA drilling moments. From Figure 14, the theoretical curve and the experimental results have the same tendency that the drilling moment of DA decreases with the increase of $n_{2}$. The theoretical model still has a good agreement with the experimental results with the RMS error of $0.089 \mathrm{Nm}$.

5.3. Discussion of $K_{11}, K_{12}$, and $K_{2}$. As can be seen from the experimental results, the drilling moments of tools are directly related to the drilling parameters including rotary speeds and penetrating velocities, and reasonable selection of these motion parameters is critical to the subsurface exploration mission. In the theory model, the drilling parameters mainly exist in the form of ratio of rotary speed and penetrating velocity. Therefore, three speed ratios $K_{11}\left(n_{11} / v_{11}\right)$, $K_{12}\left(n_{12} / v_{11}\right)$, and $K_{2}\left(n_{2} / v_{2}\right)$ are defined for discussing the effect of drilling parameters on the drilling moment requirements and power consumption of EA and DA.

According to the theoretical model, the surfaces of drilling moment requirement $M_{1}$ and power consumption $P_{1}$ of EA with $K_{11}$ and $K_{12}$ in the excavating mode are drawn as shown in Figure 15. As can be seen from Figure 15, when $1<K_{11}<2$, the driving moment decreases slowly with the increase of $K_{11}$, while the driving power consumption increases. And when $K_{11}>1$, the power consumption decreases while the drilling moment sharply increases with decreasing of $K_{11}$. Therefore, considering the drilling moment requirement and power consumption of EA, the value of $K_{11}$ is recommended in the range 


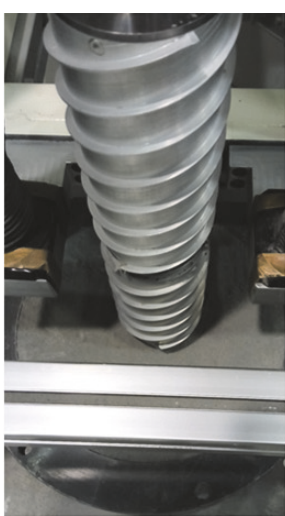

$t=0 \mathrm{~s}$

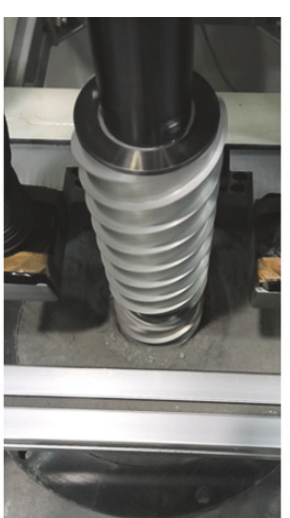

$t=270 \mathrm{~s}$

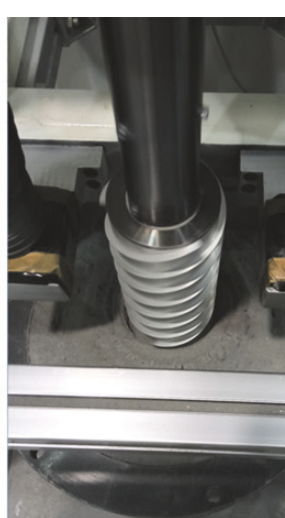

$t=540 \mathrm{~s}$

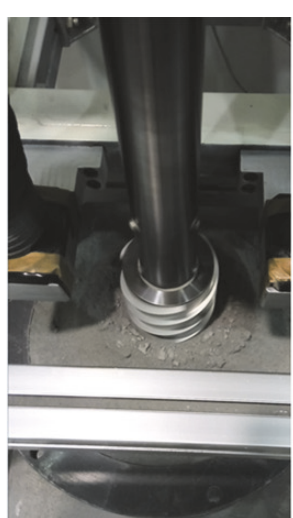

$t=810 \mathrm{~s}$

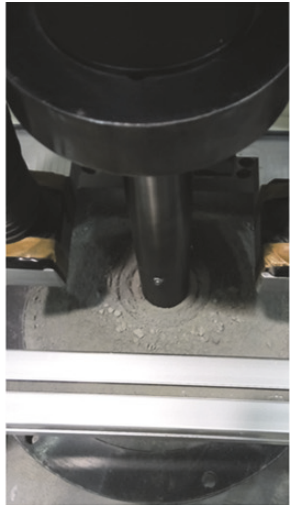

$t=1080 \mathrm{~s}$

FIGURE 11: Inchworm drilling experiments process.

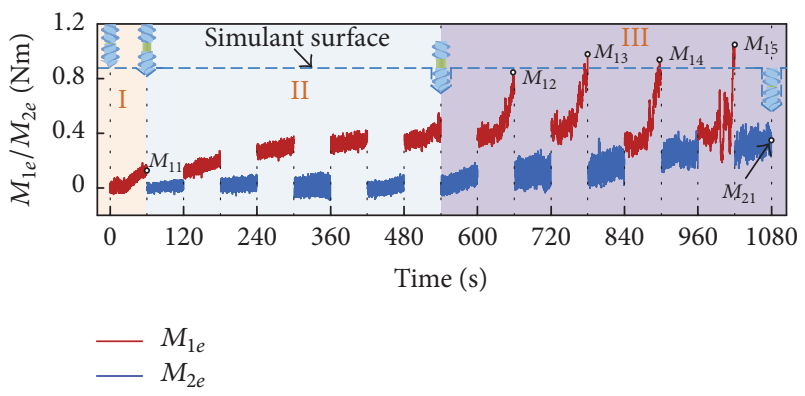

Figure 12: Drilling moments of EA and DA.
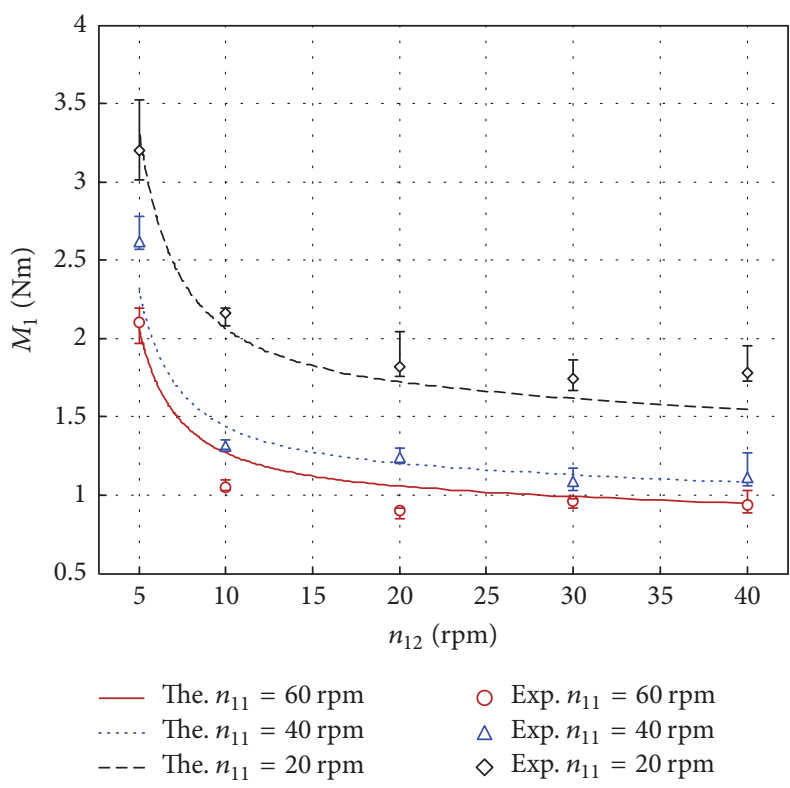

Figure 13: $M_{1}$ versus $n_{11}$ and $n_{12}$.

of $1<K_{11}<4 / 3$. For $K_{12}$, when $K_{12}<1 / 2$, drilling moment requirement and power consumption of EA increase drastically as $K_{12}$ decreases. Therefore, $K_{12}$ should satisfy the condition $K_{12}<1 / 2$ as far as possible.

The theoretical surfaces of drilling moment $M_{2}$ and power consumption $P_{2}$ of DA with $K_{2}$ in the discharging

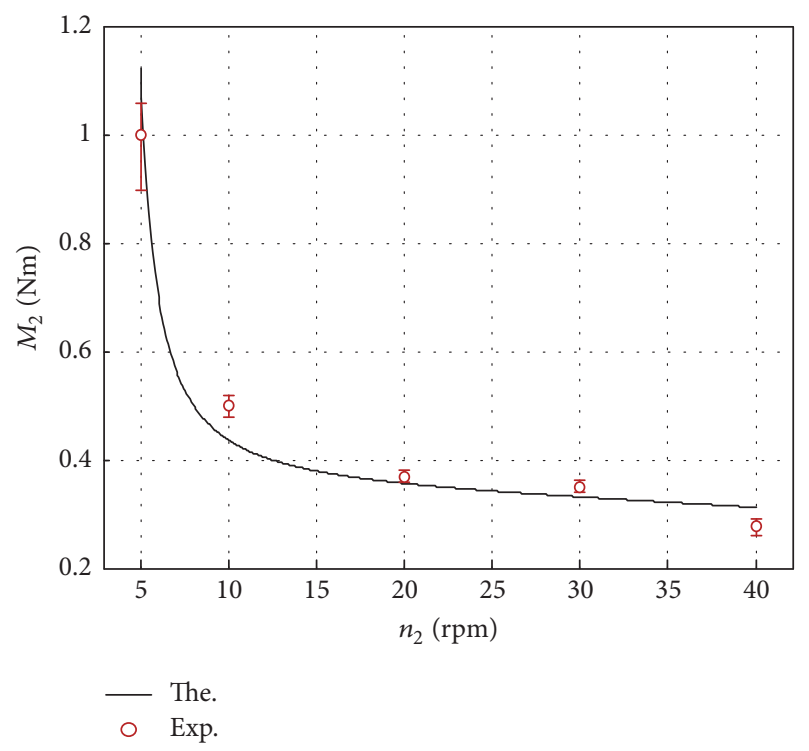

FIGURE 14: $M_{2}$ versus $n_{2}$.

mode are drawn as shown in Figure 16. As can be seen in Figure 16, when $K_{2}<1 / 3$, the drilling moment requirement $M_{2}$ increases drastically with the decrease of $K_{2}$. And when $K_{2}<1 / 3$, the power consumption $P_{2}$ increases linearly with the increase of $K_{2}$. Therefore, considering the drilling moment requirement and power consumption of $\mathrm{DA}$, the value of $K_{2}$ in the discharging mode is recommended in the range of $1 / 3<K_{2}<1 / 2$.

\section{Conclusions}

In this paper, an Inchworm Boring Robot was proposed for lunar subsurface exploration. Two auger tools of EA and DA are utilized to remove chips for IBR. For obtaining drilling characteristics of the two tools, the chips removal principles of IBR in excavating mode and discharging mode are analyzed, and then the relation of tools drilling parameters and the soil flow state in the flow channel of EA and DA are given. Subsequently, the drilling load model of tools 


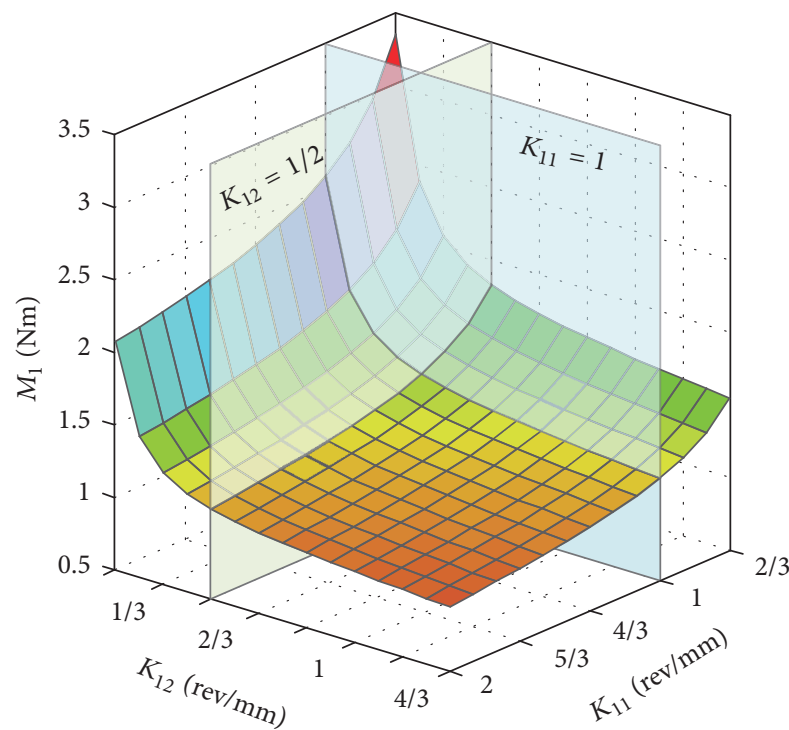

(a) $M_{1}$

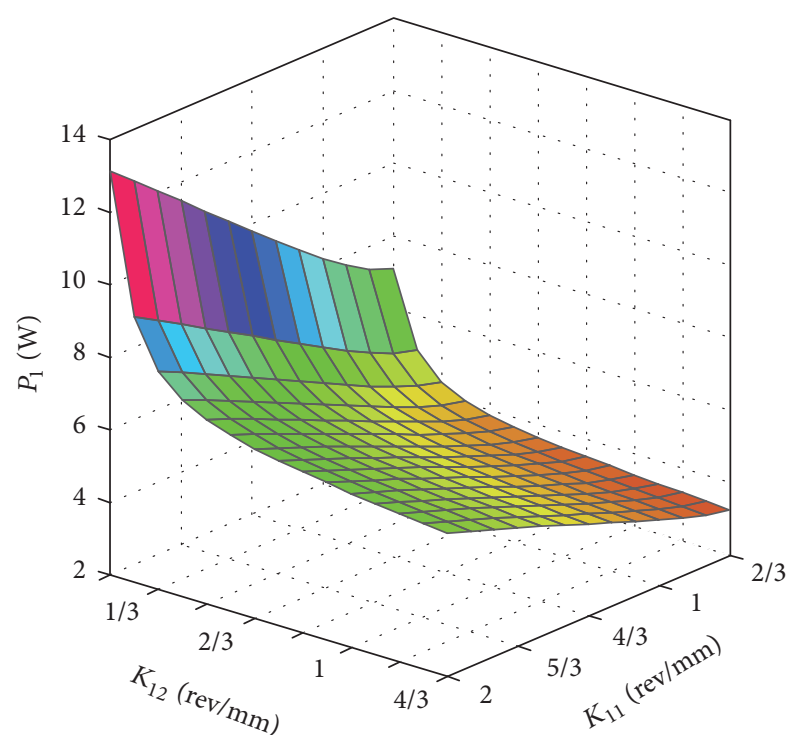

(b) $P_{1}$

Figure 15: $M_{1}$ and $P_{1}$ versus $K_{11}$ and $K_{12}$.

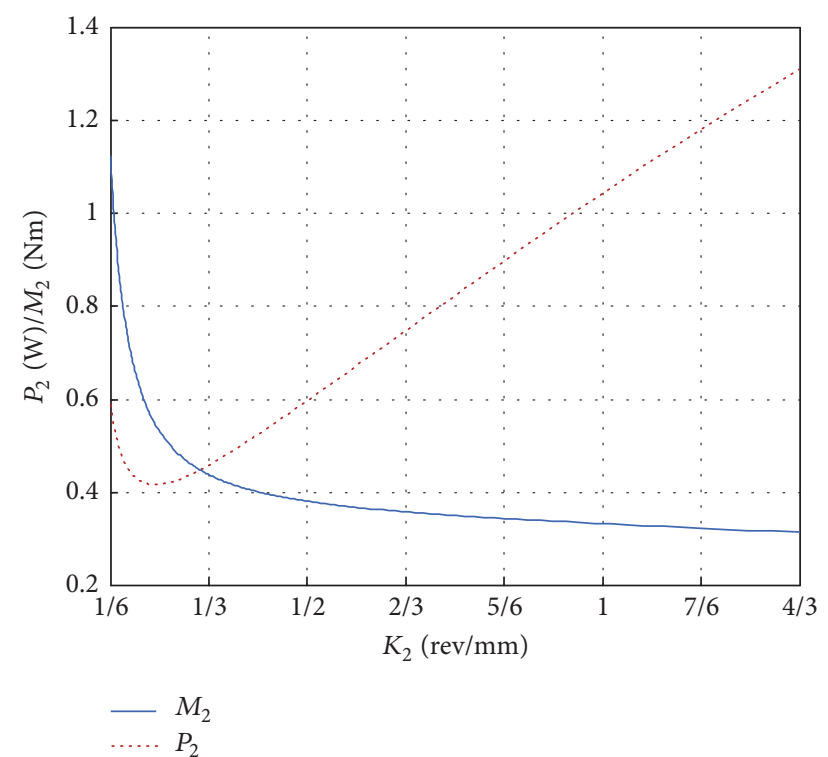

Figure 16: $M_{2}$ and $P_{2}$ versus $K_{2}$.

is further established based on the soil mechanical theory. Drilling experiments with different drilling parameters had been conducted to test the tools drilling moments, and the proposed theoretical drilling load models agree well with the experimental results within the RMS errors of $0.148 \mathrm{Nm}$. In addition, according to the theoretical model analysis, the effect of drilling parameters on the tools drilling moments and power consumption was discussed and the recommend value of speed ratios can be given as $1<K_{11}<4 / 3$, $K_{12}<1 / 2$, and $1 / 3<K_{2}<1 / 2$. These results can be used for the energy-efficient control strategy for IBR.

\section{Conflicts of Interest}

The authors declare that they have no conflicts of interest.

\section{Acknowledgments}

This work is supported by the National Natural Science Foundation of China (Grant no. 51575122) and the SelfPlanned Task of State Key Laboratory of Robotics and System (HIT) (no. SKLRS201616B).

\section{References}

[1] K. Zacny, Y. Bar-Cohen, M. Brennan et al., "Drilling systems for extraterrestrial subsurface exploration," Astrobiology, vol. 8, no. 3, pp. 665-706, 2008.

[2] I. I. Stakheev, A. V. Ivanov, and E. K. Vulfson, "Comparative characteristics of the lunar-soil particle-size distribution at the landing sites of the automatic lunar stations Luna 16 and Luna 20," Cosmic Research, vol. 14, no. 3, pp. 381-386, 1976.

[3] A. Davé, S. J. Thompson, C. P. Mckay et al., "The sample handling system for the mars icebreaker life mission: From dirt to data," Astrobiology, vol. 13, no. 4, pp. 354-369, 2013.

[4] K. Zacny, S. Nagihara, M. Hedlund et al., "Pneumatic and percussive penetration approaches for heat flow probe emplacement on robotic lunar missions," Earth, Moon and Planets, vol. 111, no. 1-2, pp. 47-77, 2013.

[5] C. R. Stoker, H. N. Cannon, S. E. Dunagan et al., "The 2005 MARTE Robotic Drilling Experiment in Río Tinto, Spain: objectives, approach, and results of a simulated mission to search for life in the Martian subsurface," Astrobiology, vol. 8, no. 5, pp. 921-945, 2008.

[6] J. W. Reiter, J. L. Guerrero, D. Wu et al., "Advanced planetary drill technology and applications to future space missions," $L p i$ Contributions, p. 1287, 2005. 
[7] Y. Bar-Cohen and K. Zacny, Drilling in Extreme Environments, Wiley-VCH Verlag GmbH \& Co. KGaA, Weinheim, Germany, 2009.

[8] K. Seweryn, K. Skocki, M. Banaszkiewicz et al., "Determining the geotechnical properties of planetary regolith using low velocity penetrometers," Planetary \& Space Science, vol. 99, no. 1, pp. 70-83, 2014.

[9] J. Grygorczuk and Ł. Wiśniewski, "Hammering Mechanism for HP3 Experiment (InSight)," in Proceedings of the 43rd Aerospace Mechanisms Symposium, pp. 415-428, NASA Ames Research, 2016.

[10] K. Seweryn, J. Grygorczuk, R. Wawrzaszek, M. Banaszkiewicz, T. Rybus, and $€$. Wiśniewski, "Low velocity penetrators (LVP) driven by hammering action-definition of the principle of operation based on numerical models and experimental tests," Acta Astronautica, vol. 99, no. 1, pp. 303-317, 2014.

[11] C. Pitcher and Y. Gao, "Analysis of drill head designs for dual-reciprocating drilling technique in planetary regoliths," Advances in Space Research, vol. 56, no. 8, pp. 1765-1776, 2015.

[12] T. Myrick, S. Frader-Thompson, J. Wilson et al., "Development of an inchworm deep subsurface platform for in situ investigation of Europa's icy shell," in Proceedings of the Workshop on Europa's Icy Shell: Past, Present, and Future, p. 7041, 2004.

[13] K. Zacny, G. Paulsen, Y. Bar-Cohen et al., "Wireline deep drill for exploration of Mars, Europa, and Enceladus," in Proceedings of 2013 IEEE Aerospace Conference, AERO 2013, usa, March 2013.

[14] H. Omori, T. Murakami, H. Nagai, T. Nakamura, and T. Kubota, "Development of a novel bio-inspired planetary subsurface explorer: initial experimental study by prototype excavator with propulsion and excavation units," IEEE/ASME Transactions on Mechatronics, vol. 18, no. 2, pp. 459-470, 2013.

[15] T. Dewei, Z. Weiwei, J. Shengyuan, S. Yi, and C. Huazhi, "Development of an Inchworm Boring Robot(IBR) for planetary subsurface exploration," in Proceedings of IEEE International Conference on Robotics and Biomimetics, IEEE-ROBIO 2015, pp. 2109-2114, chn, December 2015.

[16] W. Zhang, S. Jiang et al., "Design of a screw-cone drill for lunar regolith drilling mission," Journal of Astronautics, vol. 37, no. 12, pp. 61-69, 2016.

[17] P. Li, S. Jiang, D. Tang et al., "Design and testing of coring bits on drilling lunar rock simulant," Advances in Space Research, pp. 1-20, 2016.

[18] K. Terzaghi, Theoretical Soil Mechanics, John Wiley \& Sons, New York, NY, USA, 1965.

[19] J. M. Duncan and C. Y. Chang, "Nonlinear analysis of stress and strain in soils," Asce Soil Mechanics \& Foundation Division Journal, vol. 96, no. 5, pp. 1629-1653, 1970.

[20] R. M. Nedderman, Statics and Kinematics of Granular Materials, Cambridge University Press, 1992. 


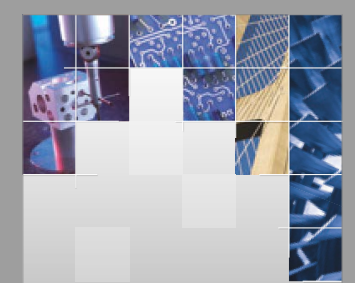

\section{Enfincering}
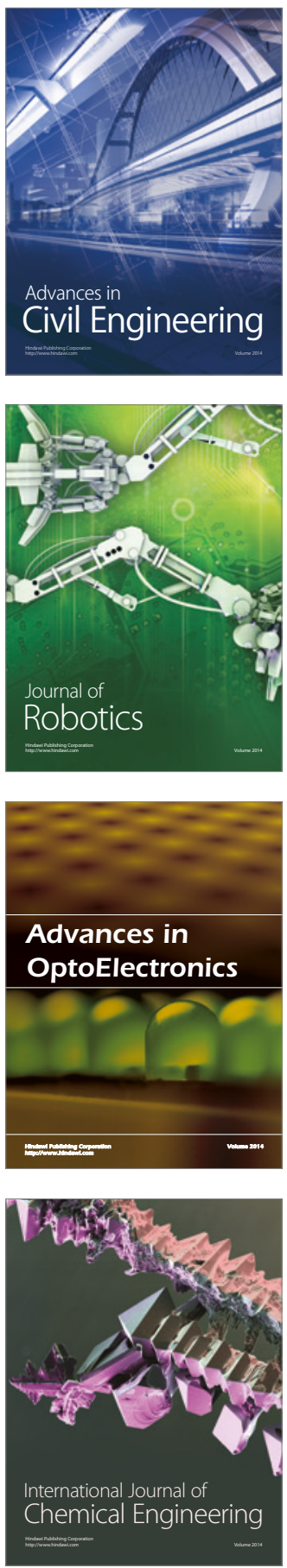

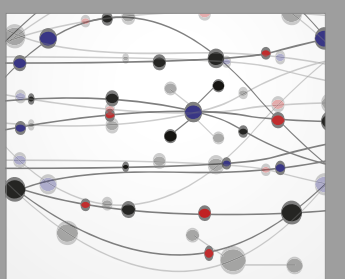

The Scientific World Journal

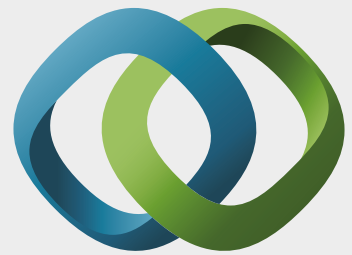

\section{Hindawi}

Submit your manuscripts at

https://www.hindawi.com
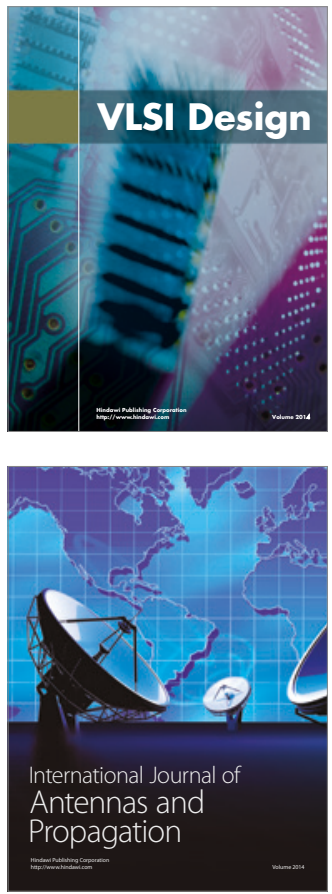

\section{Rotating}

Machinery
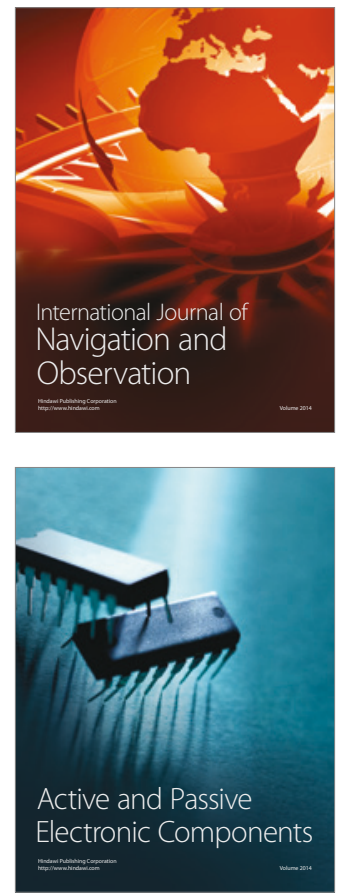
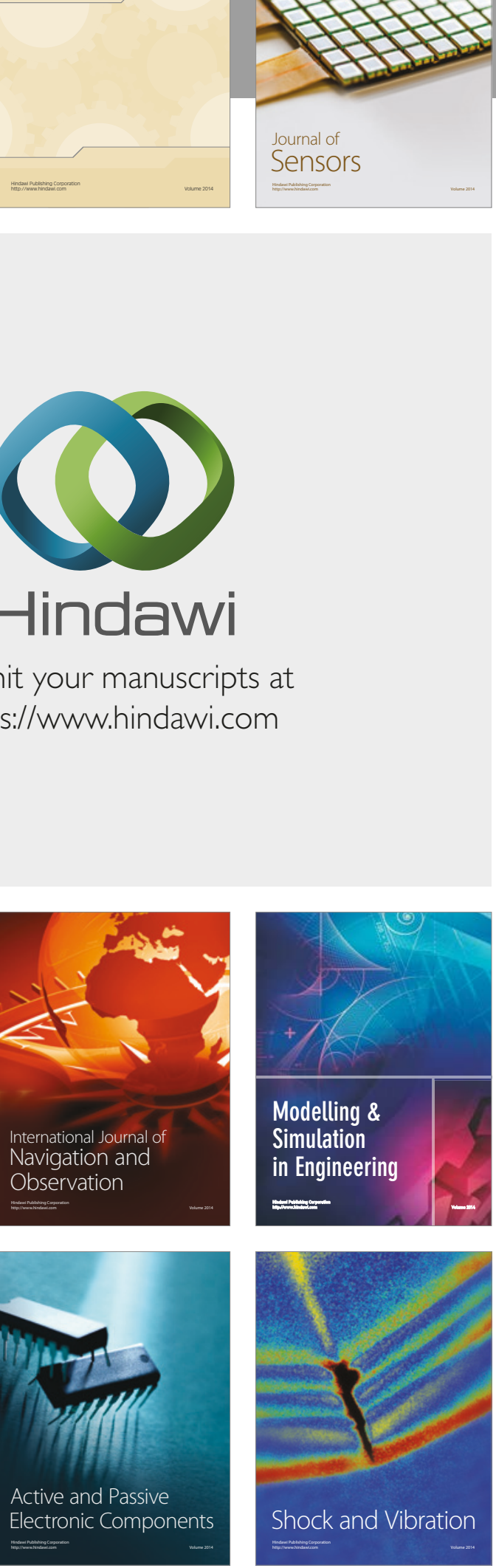
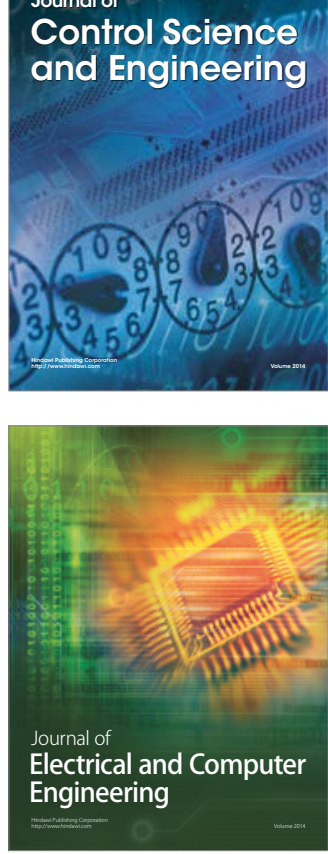

Distributed

Journal of

Control Science

and Engineering
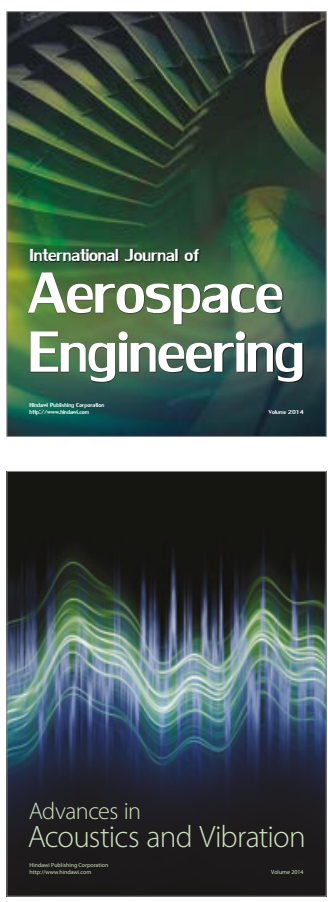

Sensor Networks 